\title{
Chronic elemental mercury intoxication: clinical and field studies in lampsocket manufacturers
}

\author{
Yu-Jen Yang, Chin-Chang Huang, Tung-Sheng Shih, Sun-Shen Yang
}

\begin{abstract}
Four workers chronically exposed to elemental mercury in a lampsocket manufacturing factory were studied. The clinical manifestations were severe in one, mild in another, and suspicious in the remaining two. Correlation between severity of clinical features and increased urinary mercury concentrations was found. The time weighted average mercury concentrations were 0.945 $\mathrm{mg} / \mathrm{m}^{3}$ and $0.709 \mathrm{mg} / \mathrm{m}^{3}$ for two workers in one room and $0.225 \mathrm{mg} / \mathrm{m}^{3}$ in the other. After stopping exposure, the workers recovered spontaneously or with D-penicillamine treatment within six months. It is concluded that recovery from chronic elemental mercury intoxication may be complete when patients are removed early from the exposure environment. The hazard of mercury intoxication in recycling of waste substances is emphasised.
\end{abstract}

(Occup Environ Med 1994;51:267-270)

Neurological damage may occur in humans after poisoning from occupational exposure to mercury compounds. Organic mercury may produce severe encephalopathy with persistent neurological disabilities ${ }^{1-4}$ or a syndrome resembling amyotrophic lateral sclerosis. ${ }^{5-6} \mathrm{By}$ contrast, exposure to inorganic or elemental mercury can also result in a disorder characterised by stomatitis, polyneuropathy, tremor and a neuropsychiatric syndrome-erethismincluding insomnia, loss of appetite, excessive shyness, emotional lability, irritability, and violent behaviour. If the disease progresses, decreased visual acuity, particularly night vision, slurred speech, disturbance of equilibrium, intention tremor, ataxic gait, and involuntary jerky movements may occur. ${ }^{7-9}$

Occupational exposure to mercury has been reported in workers in a variety of occupations including miners, furcutters, mirror makers, gilders, hatters, dentists, and manufacturers of chlorine, chloralkali, thermometers, lamps, and thermonuclear weapons. $^{7-17}$ The poisonous properties have been known for centuries but the clinical course has only been roughly described. In this paper, we report clinical and field studies on elemental mercury intoxication from a lampsocket manufacturing factory.

In August 1991, a 29 year old man from a lampsocket manufacturing factory presented, having developed nervousness, irritability, blurred vision, tremor, stuttering, unsteady gait and transient involuntary movement in the past four months. His medical and family histories were unremarkable. No history of drug abuse was noted. He first experienced gum pain, oral ulcer, dizziness, fatigue, poor attention, emotional lability, nightmares, bad temper, insomnia, body weight loss, hypersalivation, and hyperhidrosis about two years previously. On evaluation, he was alert, well oriented, but impatient, irritable, and easily angered when interviewed. His mental response was slow and short term memory was poor, probably due to inattention. General physical findings were normal except for prominent gingivitis, some dark blue lines over the gums, and sweating especially on the palms of the hands and soles of the feet. Neurological examination showed normal eye fundus and cranial nerve function. No Kayser Fleischer ring on the cornea was noted. His visual field was symmetrically constricted, however, and speech was slurred. He had dysdiadochokinesia, dysmetria, dyssynergia, postural and action tremor on both hands, and ataxic gait. The patient could not perform Tandem's walk without assistance. No masked face, rigidity, bradykinesia, dystonia, and myoclonus were noted, although he claimed occasional myoclonus. Sensation was intact and muscle strength was normal. Plantar reflexes were flexor with normal tendon reflexes. Sexual function was normal but he had a decreased sexual desire.

Laboratory tests, including complete blood cell counts, urinalysis, renal function, liver function, blood electrolytes, thyroid function, ceruloplasmin, serum copper, and 24 hour urinary copper and total protein, were normal. Electrodiagnostic studies revealed a normal electroencephalogram, electrocardiogram, somatosensory evoked potentials, brainstem auditory evoked potentials, and visual evoked potentials except for a slight prolongation of distal latencies of both median and ulnar nerves. Brain computed tomography and magnetic resonance images were unremarkable. Because the clinical pictures were similar to mercury poisoning, a heavy metal survey was performed. The mercury concentrations were $237 \mu \mathrm{g} / 1$ in blood and $610 \mu \mathrm{g} / 1$ in 24 hour urine. Lead concentrations were $45 \mu \mathrm{g} / \mathrm{dl}$ in blood and $34 \mu \mathrm{g} / 1$ in 24 hour urine. Review of his occupational history revealed that he had worked in a lampsocket manufacturing factory for five years. Exposure to heavy metals was 
suspected. Therefore, we conducted a series study to identify the aetiology and to follow up the other workers to observe the clinical course. The patient described is patient 1 of this study.

\section{Materials and methods \\ FIELD STUDY}

A walk through survey was conducted at the factory, which had been operating for eight years. Four people (three men and one woman) worked in the factory, which consisted of two rooms (A and B). In room A, two workers (workers 1 and 2) produced lampsockets by recycling the stems of white waste fluorescent lamps, which were mixed with black glass in a ratio of 15:4. In room $B$, workers 3 and 4 used waste incandescent lampstems as a source instead. Bulk smaples of waste lampstems from rooms A and B were collected and analysed. Air samples from different worksites were obtained and studied. In room $\mathbf{A}$, we monitored the fixed point air concentrations collected by an SKC low flow pump with SKC hopcalite mercury tube, and an SKC high flow pump with a mixed cellulose ester filter for 3.5 hours consecutive sampling. Six working points where the workers usually stayed were chosen and working duration was also considered based on its fixed nature. The air samples were monitored for mercury, lead, and manganese. In room B, a personal sample was collected and monitored for the same metals. ${ }^{18}$

\section{CLINICAL STUDY}

Four workers were interviewed and completed a short questionnaire asking about age, sex, duration of employment, smoking habits, alcohol consumption, work place, working time, duration of exposure, and duration of symptoms. Twenty questions were asked to

Table 1 Clinical symptoms of four workers with mercury exposure in a lampsocket manufacturing factory

\begin{tabular}{|c|c|c|c|c|}
\hline & \multicolumn{4}{|c|}{ Worker No } \\
\hline & 1 & 2 & 3 & 4 \\
\hline Age $(y) / \operatorname{sex}$ & 29/M & $27 / F$ & 21/M & 37/M \\
\hline Duration of exposure (y) & 5 & 1.5 & 3 & 7 \\
\hline Smoking & + & - & + & + \\
\hline Alcohol & + & - & + & + \\
\hline Working place & A & A & B & B \\
\hline Working time (h/day) & 10 & 4 & 8 & 8 \\
\hline Time since symptom onset $(y)$ & 2 & 2 & 1 & 1 \\
\hline \multicolumn{5}{|l|}{ Symptoms: } \\
\hline Gum pain & ++ & ++ & - & - \\
\hline Dizziness & + & + & - & - \\
\hline Fatigue & + & + & - & + \\
\hline Inattention & ++ & + & - & - \\
\hline Memory impairment & + & + & - & + \\
\hline Bad temper & + & + & - & - \\
\hline Irritability & ++ & + & - & - \\
\hline Back pain & + & - & - & - \\
\hline Nightmare/insomnia & + & - & + & - \\
\hline Body weight loss & + & - & - & - \\
\hline Hyperhidrosis & ++ & + & + & - \\
\hline Hypersalivation & + & + & + & - \\
\hline Blurred vision & + & - & - & - \\
\hline Tremor & ++ & - & - & - \\
\hline Writing difficulty & ++ & - & - & - \\
\hline Stuttering & + & - & - & - \\
\hline Slow mental response & + & - & - & - \\
\hline Unsteady gait & +++ & - & - & - \\
\hline Numbness & + & + & - & - \\
\hline
\end{tabular}

+++ Severe; ++ moderate; + mild; - absent; $\mathbf{A}=\operatorname{room} \mathbf{A} ; \mathbf{B}=$ room $\mathbf{B}$. detect clinical symptoms such as gum pain, dizziness, fatigue, memory impairment, bad temper, irritability, back pain, nightmare, insomnia, body weight loss, excessive salivation, hyperhidrosis, blurred vision, tremor, writing difficulty, slurred speech, mental response, unsteady gait, and distal limb numbness. The clinical symptoms were estimated semiquantitatively by the workers. Detailed physical and neurological assessments were performed on each worker by two neurologists. Special attention was placed on visual field defects, gingivitis, dysarthria, tremor, finger to nose test, heel to knee and shin test, gait disturbance, muscle strength, and tendon reflexes. A modified minimental test (total score of 30 points) was also given. Serial blood and urine samples were collected for detection of lead and mercury and for tests of renal function. All workers were followed up and the clinical pictures were charted after cessation of exposure. The clearance of mercury from blood was also studied.

\section{Results}

\section{FIELD STUDY}

During the walk in survey, some silver-like possible mercury droplets were found on the floor, window, and the surface of a fan which was located $50 \mathrm{~cm}$ away from a crucible furnace in room $A$. The bulk samples from room A revealed that the white waste fluorescent lampstems contained lead and mercury and the black glass contained manganese. The bulk samples from room B showed no mercury, although lead and manganese were found. In room A $\left(32.3 \mathrm{~m}^{2}\right)$, the time weighted average (TWA) mercury exposure concentrations calculated from the most common work areas were $0.945 \mathrm{mg} / \mathrm{m}^{3}$ for worker 1 and $0.709 \mathrm{mg} / \mathrm{m}^{3}$ for worker 2 . In room B $\left(15 \cdot 1 \mathrm{~m}^{2}\right)$, the personal TWA concentration of mercury was $0.225 \mathrm{mg} / \mathrm{m}^{3}$. The highest exposure concentrations were $0.064 \mathrm{mg} / \mathrm{m}^{3}$ for lead and $<0.001 \mathrm{mg} / \mathrm{m}^{3}$ for manganese.

\section{CLINICAL STUDY}

Table 1 summarises the clinical symptoms of the four workers with elemental mercury exposure. There were three men and one woman and their ages ranged from 21 to 37 years. The durations of exposure were from 1.5 to seven years. Three workers drank alcohol socially and smoked. The working times were usually between eight and 10 hours a day except for worker 2 who worked on average four hours a day. The duration of symptoms ranged from one to two years. Workers 1 and 2 usually stayed in room A where a high air mercury concentration was noted. The prodromal symptoms were usually nonspecific and included fatigue, memory impairment, hypersalivation, hyperhidrosis, and insomnia. Early symptoms of gum pain, dizziness, poor attention, bad temper, and irritability were found in two workers. Late manifestations of blurred vision, dysarthria, 
Table 2 Clinical signs and mercury concentration of four workers with mercury exposure in a lampsocket manufacturing factory

\begin{tabular}{|c|c|c|c|c|}
\hline & \multicolumn{4}{|c|}{ Worker No } \\
\hline & 1 & 2 & 3 & 4 \\
\hline Gingivitis & ++ & + & - & - \\
\hline Postural tremor & ++ & - & - & - \\
\hline Action tremor & ++ & - & - & - \\
\hline Dysarthria & + & - & - & - \\
\hline Ataxia & +++ & - & - & - \\
\hline Dysmetria/dyssynergia & ++ & - & - & - \\
\hline Visual field constriction & + & - & - & - \\
\hline Muscle strength & $\mathbf{N}$ & $\mathbf{N}$ & $\mathbf{N}$ & $\mathbf{N}$ \\
\hline Tendon reflex & $\mathbf{N}$ & $\mathrm{N}$ & $\mathrm{N}$ & $\mathbf{N}$ \\
\hline Minimental test ${ }^{\star}$ & 29 & 30 & 30 & 30 \\
\hline \multicolumn{5}{|l|}{ Mercury concentration: } \\
\hline Blood $(\mu \mathrm{g} / \mathrm{l})$ & 237 & 105 & $<1$ & 15 \\
\hline 24 hour urine $(\mu \mathrm{g} / 1)$ & 610 & 408 & $110 t$ & $90 \dagger$ \\
\hline
\end{tabular}

+++ severe; ++ moderate; + mild; - absent; $\mathbf{N}=$ normal, ${ }^{\star}$ total score $30 ;$ tspot urine.

tremor, unsteady gait, and slow mental response were present in one. Table 2 shows the clinical signs in the four workers. Only worker 1 had prominent neurological signs. The tremor was usually postural and intentional. Other positive neurological signs included dysarthria, ataxia, dysmetria, and visual field constriction. Worker 2 only had gingivitis. No other signs were noted in the remaining workers. The minimental test was normal.

Blood mercury concentrations were high with $237 \mu \mathrm{g} / 1$ in worker 1 and $105 \mu \mathrm{g} / 1$ in worker 2 (reference range $<10 \mu \mathrm{g} / \mathrm{l}$ ). The 24 hour urinary mercury concentrations were $610 \mu \mathrm{g} / 1$ in worker 1 and $408 \mu \mathrm{g} / 1$ in worker 2 , and spot samples contained $110 \mu \mathrm{g} / 1$ in worker 3 and $90 \mu \mathrm{g} / 1$ in worker 4 (reference range $<20 \mu \mathrm{g} / \mathrm{l}$ ). Worker 1 had a blood lead concentration of $45 \mu \mathrm{g} / 1$ and 24 hour urinary lead of $34 \mu \mathrm{g} / 1$ (reference range $<20 \mu \mathrm{g} / 1$ in blood and $<80 \mu \mathrm{g} / 1$ in urine). All four workers had normal renal function tests and no proteinuria.

\section{CLINICAL RECOVERY}

Because worker 1 had prominent symptoms, D-penicillamine $(150 \mathrm{mg}$ per day for one week and then $300 \mathrm{mg}$ per day for seven weeks) was given. His unsteady gait improved rapidly within two weeks and had disap-

6 August 1991
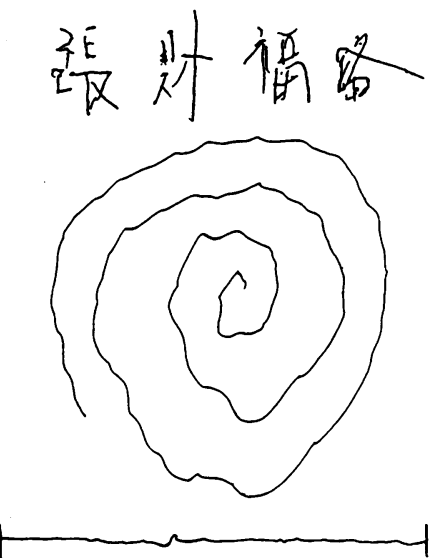

Figure 1 Handwriting of worker 1 before (6 August 1991) and after (30 October 1991) $D$-penicillamine treatment showing improvement.

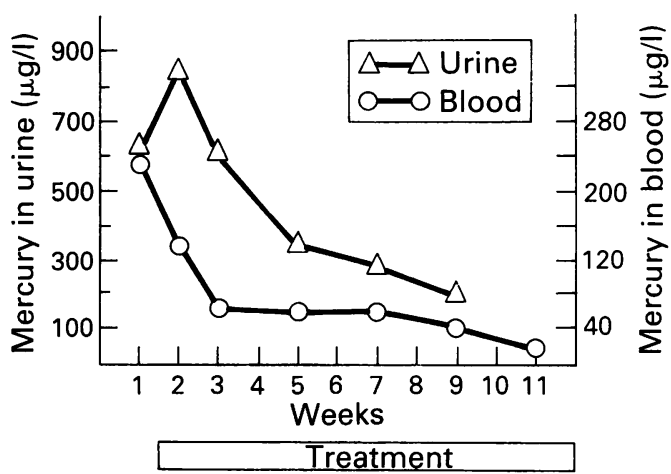

Figure 2 Monitoring of mercury concentrations in worker 1 .

peared two months later, whereas the improvement of action tremor was slower and took four months to disappear. In the other three workers, the clinical symptoms also disappeared about two months after cessation of exposure. Figure 1 shows the improvement in writing for worker 1 . With D-penicillamine treatment, blood mercury concentrations in worker 1 showed a rapid decrease in the first two weeks and then slowly returned to normal in the next eight weeks. Monitoring of 24 hour urinary mercury showed an increase in the first week and a slow decrease within two months (fig 2).

\section{Discussion}

The present study reports the clinical course of elemental mercury intoxication. The diagnosis was based on clinical manifestations and measurements of mercury in blood, urine, and air. Two workers had overt clinical symptoms and the other two had few symptoms, a difference possibly related to the degree of mercury exposure. It seems that in the early stage, prodromal symptoms such as fatigue, memory impairment, hypersalivation, and hyperhidrosis may occur. Within a few months, they may be followed by gum pain, poor attention, bad temper, irritability, and other psychiatric symptoms. If the exposure continues, tremor, blurred vision, dysarthria, unsteady gait, and distal numbness may occur. After cessation of exposure, our patients recovered spontaneously or with $D$ penicillamine treatment within three to six months. We elected to use only a low dose of D-penicillamine $(150-300 \mathrm{mg} /$ day $)$ due to its potential side effects. Dimercaptosuccinic acid (DMSA) has been proved to be more appropriate in chelating heavy metals. ${ }^{19}$ The benefit is still controversial however, because there is no clear evidence that DMSA could remove mercury from the brain. ${ }^{20}$ Although some studies reported persisting neurological sequels, ${ }^{7}$ the prognosis seemed better than in organic mercury intoxication. Firstly, gait disturbance improved followed by tremor and writing difficulty. Generally, if the urinary mercury concentration is above $300 \mu \mathrm{g} / \mathrm{l}$, the clinical evidence of poisoning may become evident. ${ }^{21}$ Our study confirmed this finding. Worker 1 had the most severe neurological symptoms and signs, and worker 2 the next 
most severe, presumably because they worked in room $A$ where the air concentration of mercury was much higher. For worker 1 the clinical recovery was proportional to the decrease of blood and 24 hour urinary mercury concentrations.

The highest air lead concentration was $0.064 \mathrm{mg} / \mathrm{m}^{3}$ (threshold limit value: 0.15 $\left.\mathrm{mg} / \mathrm{m}^{3}\right) .{ }^{22}$ Also, the serum lead concentration was slightly raised in worker 1 . Did lead play a role in this outbreak? Lead poisoning is usually characterised by abdominal pain, polyneuropathy, and diffuse encephalopathy such as seizures, increased intracranial pressure, mental defect, and even loss of consciousness. ${ }^{23-25}$ It is unusual for lead poisoning to cause tremor and cerebellar dysfunction. Therefore, we conclude that mercury intoxication is the main causative agent. Whether there is a synergistic effect of lead on mercury intoxication remains unknown, however, and further investigation is warranted.

This report is the first of an outbreak of elemental mercury intoxication in Taiwan due to occupational exposure. The affected workers produced lampsockets and used recycled waste lampstems containing mercury. This work is not well controlled by the Environmental Protection Agency in Taiwan. The hazard of the toxic substance was not announced and workers were not educated in protection measures. We understand that similar small lampsocket factories have been established in other south east Asian countries and mainland China. We hope that this occupational disease will not occur in these countries and the hazard is recognised and prevented.

1 Hunter D, Bomford RR, Russel DS. Poisoning by methyl mercury compounds. $Q$ F Med 1940;9:193-213.

2 Hunter D, Russel DS. Focal cerebral and cerebellar atrophy in a human subject due to organic mercury comphy in a human subject due to organic mercury com-

3 McAlpine D, Araki S. Minamata disease: an unusual neurological disorder caused by contaminated fish. Lancet 1958;ii:629-31.
4 Bakir F, Damluji SF, Amin-Zaki L, et al. Methylmercury poisoning in Iraq. Science 1973;181:230-41.

5 Kantariiam AD. A syndrome resembling ALS following chronic mercurialism. Neurology 1961;11:639-44.

6 Brown IA. Chronic mercurialism: a cause of the clinical syndrome of amyotrophic lateral sclerosis. Archives of Neurology and Psychiatry 1954;72:674-81.

7 Vroom FQ, Greer M. Mercury vapour intoxication. Brain 1972;95:305-18.

8 Neal PA, Jones PR. Chronic mercurialism in the hatter's furcutting industry. $7 \mathrm{Am}$ Med Wom Assoc 1938;110. 337-43.

9 Kark R. Clinical and neurochemical aspects of inorganic mercury intoxication. In: Vinken P, Bruyn G, eds. Handbook of clinical neurology, vol 36. New York: Elsevier North-Holland Biochemical Press, 1979: 147-97.

10 Albers JW, Cavender GD, Levine SP, Langolf GD Asymptomatic sensorimotor polyneuropathy in workers exposed to elemental mercury. Neurology 1982;32: 1168-74.

11 Smith PJ, Langolf GD, Goldberg J. Effects of occupational exposure to elemental mercury on short term memory. Br f Ind Med 1983;40:413-9.

12 Wood RW, Weiss AB, Weiss B. Hand tremor induced by industrial exposure to inorganic mercury. Arch Environ Health 1973;26:249-52.

13 Fawer RF, Ribaupierre YD, Guillemin MP, Berode M, Lob $M$. Measurement of hand tremor induced by industrial exposure to metallic mercury. $\mathrm{Br} \mathrm{F}$ Ind $\mathrm{Med}$ 1983;40:204-8.

14 Piikivi L, Tolonen U. EEG findings in chlor-alkali workers subjected to low long term exposure to mercury vapour. $\mathrm{Br} \mathcal{F}$ Ind $\mathrm{Med}$ 1989;46:370-5.

15 Albers JW, Kallenbach LR, Fine LJ, et al. Neurological abnormalities associated with remote occupational elemental mercury exposure. Ann Neurol 1988;24:651-9.

16 Iyer K, Goodgold J, Eberstein A, Berg P. Mercury poisoning in a dentist. Arch Neurol 1976;33:788-90.

17 Shapiro IM, Cornblath DR, Sumner AJ, et al. Neurophysiological and neuropsychological function in mercury-exposed dentists. Lancet 1982;1:1147-50.

18 National Institute for Occupational Safety and Health Manual of analytic methods-method 6009 for mercury. 3rd ed. Cincinnati, Ohio: NIOSH, 1989:6009.

19 Aposhian HV. DMSA and DMPS-Water soluble antidotes for heavy metal poisoning. Annu Rev Pharmacol Toxicol 1983;23:193-215.

20 Buchet JP, Lauwerys RR. Influence of 2,3-dimercaptopropane-1-sulfonate and dimercaptosuccinic acid on the mobilization of mercury from tissues of rats pretreated with mercuric chloride, phenylmercury acetate or merwith mercuric chloride, phenylmercury
cury vapors. Toxicology 1989;54:323-33.

21 West I, Lim J. Mercury poisoning among workers in California's mercury mills. $f$ Occup Med 1968;10 697-701.

22 American Conference of Governmental Industria Hygienists. Threshold limit values for chemical substances in the work environment adopted by ACGIH. Cincinnati, Ohio: ACGIH, 1990:27-8.

23 Baker EL, Landrigan PJ, Barbour AG, et al. Occupationa lead poisoning in the United States. $\mathrm{Br} F$ Ind $\mathrm{Med}$ 1979;36:314-22.

24 Beattie AD, Moore MR, Goldber A, et al. Role of chronic low-level lead exposure in the etiology of mental retarlow-level lead exposure in the

25 Baker EL, Feldman RG, White RA, et al. Occupationa lead neurotoxicity: a behavioral and electrophysiological evaluation. Brf Ind Med 1984;41:352-61. 